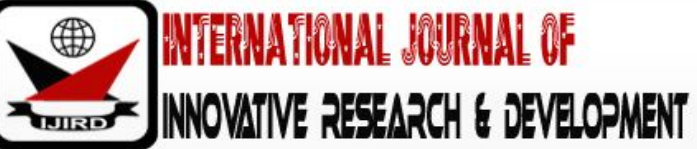

ISSN 2278 - 0211 (Online)

\section{Detection of Metallo-Beta-Lactamase Producing Bacteria in Some Sachet Water Sold within Calabar Metropolis, Nigeria}

\author{
Andy, Iniobong E. \\ Senior Lecturer, Department of Microbiology, University of Calabar \\ Archibong, Charles Patrick \\ Post Graduate Student, Department of Microbiology, University of Calabar
}

\begin{abstract}
:
Bacterial antibiotics resistance is a recurring problem that have resulted in increased morbidity and mortality rates over the decades. The Metallo-beta-lactamase (MBL) producing bacteria show resistance to carbapenems and most beta lactams, hence, constituting a major threat to an effective bacterial chemotherapy especially among the neonates, immune compromised and the senescent. This study was carried out to detect MBL producing bacteria in different brands of sachet water sold within Calabar metropolis. From a total of 10 different brands of sachet water samples, 50 non-duplicate gramnegative bacterial isolates of Acinetobacter $\operatorname{spp}(n=1)$, Aeromonas spp $(n=6)$, Citrobacter spp (6), Enterobacter $\operatorname{spp}(n=6)$, Escherichia spp $(n=2)$, Klebsiella spp $(n=2)$, Plesiomonas spp $(n=2)$, Proteus spp $(n=3)$, Pseudomonas $\operatorname{spp}(n=2)$, Salmonella $\operatorname{spp}(n=3)$, Serratia spp $(n=2)$ were tested for susceptibility to imipenem using disk diffusion method. Among the isolates, $35(70 \%)$ showed full and intermediate resistance to imipenem; 10(29\%) showed MBL production by the DDST and 19(54\%) via the CDT method while 7(20\%) were confirmed MBL producer using both phenotypic methods. Statistical comparison of both methods using the student $t$ test showed no significance $(p>0.05)$. All the isolates were only susceptible to streptomycin and showed resistance to orfloxacin, gentamycin, augmentin, ceftazidime and cefuroxime. The multiple antibiotics resistance indices of these isolates ranged from 0.5-0.8. The presence of these MBL producing bacteria in sachet water which are widely consumed is a potential threat to public health as the genes encoding MBL can be transferred to human commensals and pathogens. This could contribute to the failure in the use of carbapenems and other beta lactam antibiotics for treatment of infections.
\end{abstract}

Keywords: Antibiotics, Metallo-beta Lactamases

\section{Introduction}

Bacterial antibiotics resistance ever since the discovery of antibiotics is a global challenge to human health and chemotherapy. As a result, several antibiotics that were once potent for treatment and management of infections are no longer effective thereby resulting in increased morbidity and mortality rates as well as increased cost of treatment (Niederman, 2001). Bacterial antibiotics resistance could be attributed to the intrinsic traits or genetically acquired traits which confer resistance to different classes of antibiotics used for chemotherapy. These resistant mechanisms include reduced outer-membrane permeability in gram-negative bacteria, efflux pumps, absence of antibiotics target, altered antibiotics targets, chemical modification of antibiotics.

Several bacterial enzymes such as beta lactamases and aminoglycosidases modify antibiotics via hydrolysis or transfer of chemical groups. Enzyme mediated antibiotics resistance is a major mechanism of resistance, for instance the beta lactamases were associated with resistance to the pencillins, one of the earliest discovered antibiotics (Blair et al., 2015). The beta lactmases have been described as the most diverse class of proteins to be described (Philippon et al., 2016). These enzymes are of great clinical significance and have huge impact on health, hence efforts have been directed to the classification of the beta lactamases for enhanced understanding and studies (Ambler, 1991; Hall and Barlow, 2003; Bush, 2013). Different classification schemes exist for grouping of the beta lactamases (Bush and Jacoby, 2010). According to the Ambler's classification scheme, the beta lactamases are grouped into four categories (A, B, C, and D). These subclasses of beta lactamases detoxify various beta lactam antibiotics like cepahalosporins, monobactams, penicillins, carbapenems (Livermore, 2008; Nordmann et al., 2011; Voulgari et al., 2013). The classes A, C and D are known as the serine based beta lactamases and the class B beta lactamases are the metallo-beta lactamases.

The metallo-beta-lactamases (MBL) hydrolyze the carbapenems and most of beta lactams except the aztreonam. They are further classified into three subclasses (B1, B2 and B3) based on data regarding the conserved sequences (Hall and Barlow, 2003; Alderson et al 2014). The MBL unlike other beta lactamases are not inhibited by any known clinical inhibitors like clavulanic acid, thiol compounds and mercaptans (Bebrone, 2007). This further makes it a major challenge to therapy and treatment of severe infections caused by MBL producing pathogens. The rapid spread of the MBL producing bacteria have been reported worldwide and this can be attributed to the frequent use of carbapenems for treating 
infections associated with extended spectrum beta lactamases (ESBL) producing bacteria as well the indiscriminate use because of its broad spectrum of activity (Tzouvelekis et al., 2012; Queenan and Bush, 2007, Paphitou, 2013). Early detection of MBL during diagnosis of serious infections is very vital for treatment of such infections (Senda et al., 1996; Navaneeth et al., 2002; Jesudason et al., 2005).Several phenotypic methods of MBL detection have been developed (Behera et al., 2008; Franklin et al., 2006). These detection methods are based on the use of chelating agent like the EDTA which binds the zinc ions which are required for activity of the enzyme (Wanget al., 1999).

Water has been described as a reservoir of antibiotics resistance and also a major route for transmission of microorganisms and diseases (Baquero et al., 2008; Martínez, 2008). As a result, bacteria capable of producing MBLs can be passed from drinking water to humans and the genes encoding MBL production can be transferred between the environmental bacteria in the water and human commensals and pathogens (Poirel et al., 2005; Hocquet, et al., 2016; Cantas et al., 2013). Acquisition of these genes by human pathogens can result in difficulty in treatment of such infections especially among the neonates, immunocompromised and the aged. Hence, this study was carried out in order to assess the antibiogram and the occurrence of MBL producing bacteria in vended drinking sachet water sold within Calabar metropolis.

\section{Materials and Methods}

\subsection{Sample Collection}

Ten sachet water samples, randomly collected in sterile bottles from ten different manufacturers within Calabar metropolis were analysed in duplicates within $18 \mathrm{~h}$ of sample collection.

\subsection{Isolation, Purification and Identification of Isolates}

For the sachet water samples, $1 \mathrm{ml}$ of the samples were plated on sterile MacConkey and Nutrient agar plates and incubated for $24 \mathrm{~h}$ at $37^{\circ} \mathrm{C}$. The distinct colonies were aseptically picked with a sterile straight wire loop and purified by streaking on freshly prepared nutrient and MacConkey agar plates which were incubated for $24 \mathrm{~h}$ at $37^{\circ} \mathrm{C}$. The pure colonies were subsequently streaked on a nutrient agar slant overlaid with sterilized mineral oil for further analysis. In line with the bacterial identification procedures in Bergey's manual of determinative bacteriology (2015), The following biochemical tests were carried out to characterize the isolates: Grams staining, oxidase, sugar fermentation, citrate, urease, catalase, Motility Indole Ornithine (MIO), and Methyl Red (MR) tests. The isolates were identified by comparing the macroscopic, cultural, physiological and biochemical characteristics with Bergey's manual of determinative bacteriology (2015).

\subsection{Screening for Imipenem Resistant and Intermediate Resistant Isolates}

The imipenem resistance was determined by the agar diffusion method following the Clinical Laboratory standard Institute (CLSI) guidelines (2006). A $24 \mathrm{~h}$ broth culture of the bacterial isolates matching 0.5 Macfarland standard were swapped on a Muller Hinton agar plate and $10 \mu \mathrm{g}$ imipenem disk placed on the agar surface and incubated for $24 \mathrm{~h}$ at $37^{\circ} \mathrm{C}$. After 24h incubation period, the diameter of the zones of inhibition around imipenem disks were measured and compared with CLSI standards to determine the degree of sensitivity and resistance. Isolates were considered to be imipenem resistant when the zone around imipenem disk were $13 \mathrm{~mm}$, intermediate resistant, 14-15 $\mathrm{mm}$ and susceptible to imipenem when zone of inhibition is $\geq 16 \mathrm{~mm}$.

2.4. Phenotypic Detection of Metallo-Beta-Lactamase (MBL) Production among the Imipenem Resistant and Intermediate Resistant Isolates

Two phenotypic methods - Imipenem EDTA Double disk synergy test (DDST) and combined disk test (CDT) used by Bhalero et al (2010) were adopted for the detection of metallo-beta-lactamase production among the isolates. Using Imipenem EDTA Double disk synergy test, isolates were inoculated on Muller Hinton agar plates. A $10 \mu \mathrm{g}$ Imipenem disk was placed $20 \mathrm{~mm}$ center to center from a blank disk containing $10 \mu \mathrm{L}$ of $0.5 \mathrm{M}$ EDTA (750 $\mu \mathrm{g})$. Enhancement of the zone of inhibition on the far side of the disk showed possible MBL production.

Imipenem - EDTA combined disk test was carried out by inoculating the test organisms on Muller Hinton agar plates. Two $10 \mu \mathrm{g}$ imipenem disks were placed on the plates and $10 \mu \mathrm{L}$ of EDTA solution was added to one of the disks to get the desired concentration of $750 \mu \mathrm{g}$. The inhibition zones were compared after $16-18 \mathrm{~h}$ of incubation at $35^{\circ} \mathrm{C}$. A $7 \mathrm{~mm}$ increase in the inhibition zone of Imipenem-EDTA disk was indicative of MBL production.

\subsection{Statistical Analysis}

The SPSS software version 21 was used for analysis of the results from this study

\section{Results}

Thirty-five (35) bacterial isolates were screened for metallo-beta-lactamase (MBL) production using two phenotypic methods, imipenem double disk synergy test (DDST) (Figure 1) and combined disk test (CDT) (Figure 2). Using the DDST, 10(29\%) of the isolates showed MBL production and 19(54\%) were MBL producers using the CDT while $6(17 \%)$ of the imipenem resistant isolates were non MBL producers. Using both phenotypic tests, $7(20 \%)$ of the imipenem resistant isolates were confirmed to be MBL producers (table 1). There was significance difference in the results obtained from both DDST and CDT test. The antibiotics susceptibility testing of the seven isolates confirmed to be MBL producers are shown in Figure 3. Out of a total of 13 antibiotics used in the study, all the isolates were resistant to cefuroxime, 
ceftazidime, augmentin, gentamycin and orfloxacin but susceptible to only streptomycin. From table 2 , the isolates showed resistance to many antibiotics. Citrobacter spp and Pseudomonas spp had the highest resistance profile, each of the isolate showed resistance to ten antibiotics. The least resistance profile was recorded against Aeromonas spp which was resistant to six antibiotics. The Multiple antibiotics resistance indices (MARI) result of all the isolates ranged from 0.5-0.8.

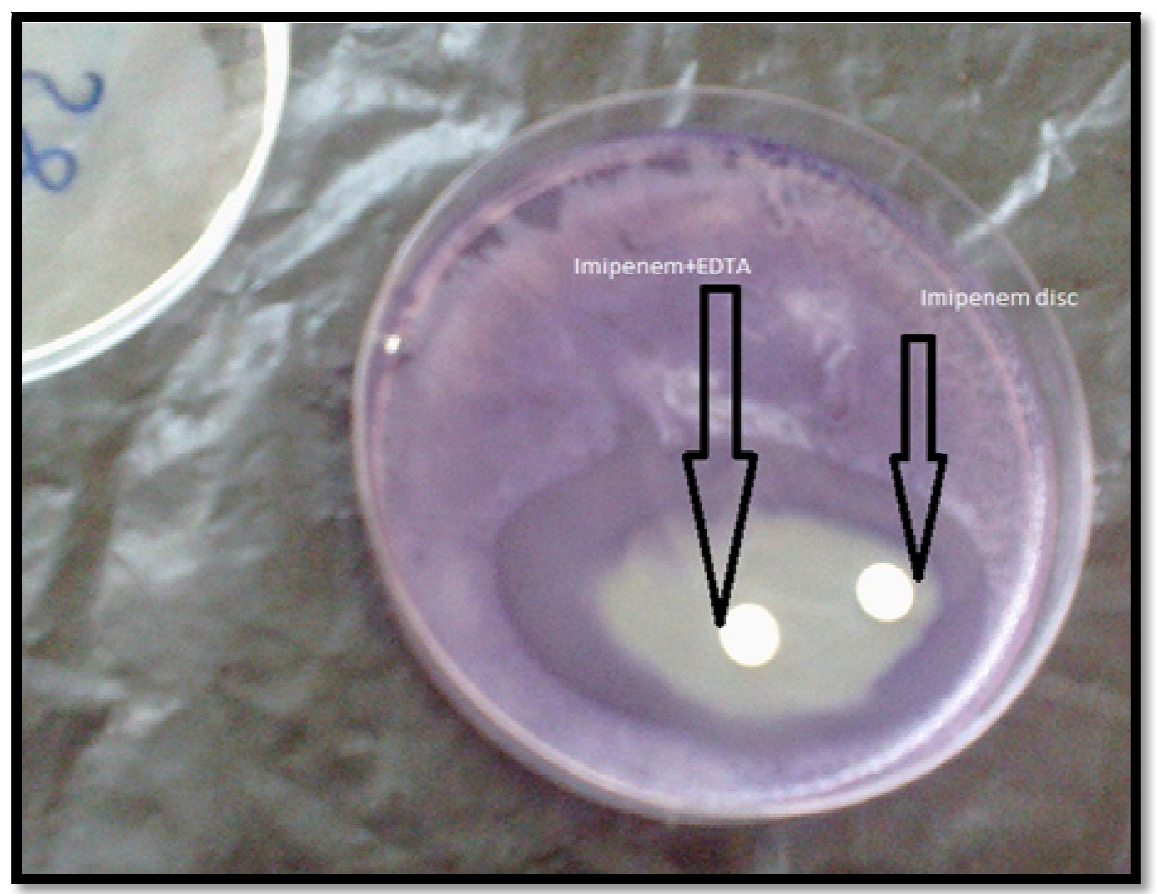

Figure 1: DDST Phenotypic Test for Detection of MBL

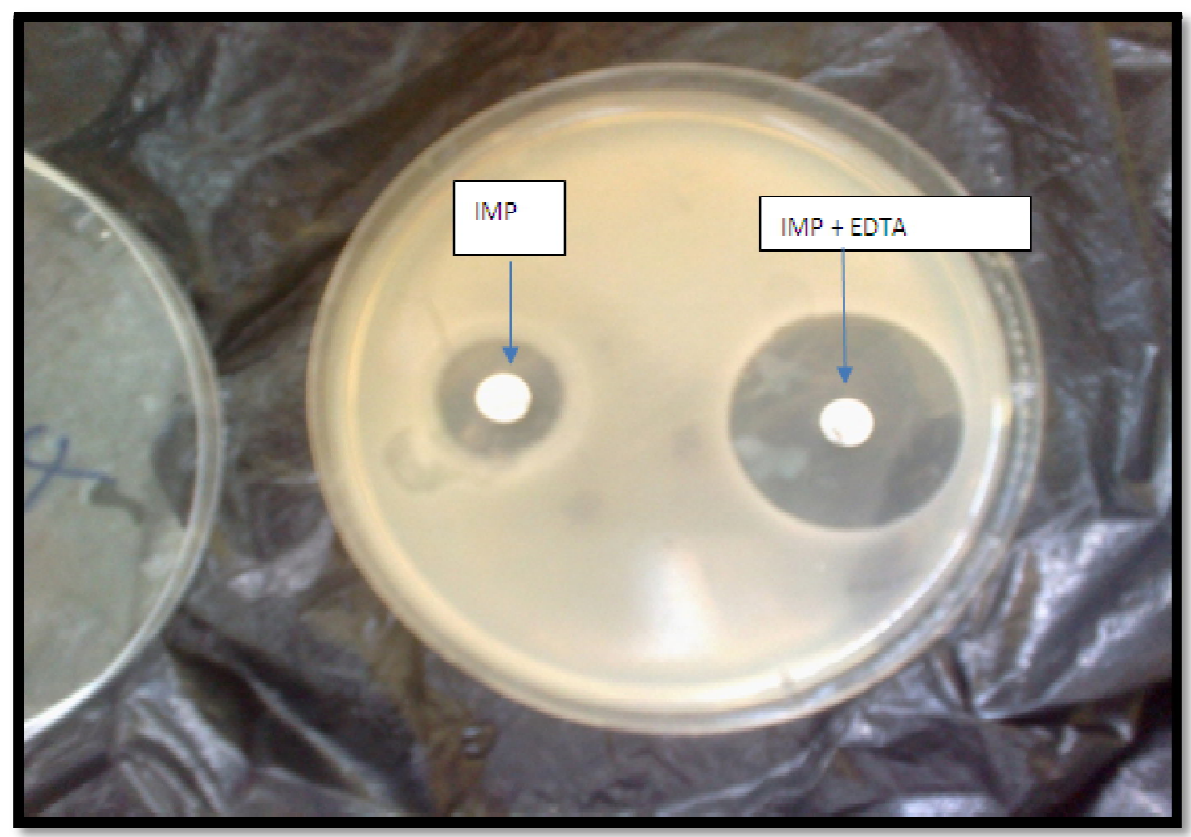

Figure 2: Combined Disk Test (CDT) for Phenotypic Detection of Metallo-Beta-Lactamase (MBL)

\begin{tabular}{|c|c|}
\hline Phenotypic test & Number of MBL positive isolates n(\% ) \\
\hline DDST & $10(29)$ \\
\hline CDT & $19(54)$ \\
\hline DDST and CDT & $7(20)$ \\
\hline \\
Table 1: Mblphenotypic Screening Using DDST and CDT Phenotypic \\
Tests for Isolates from Sachet Water Samples
\end{tabular}




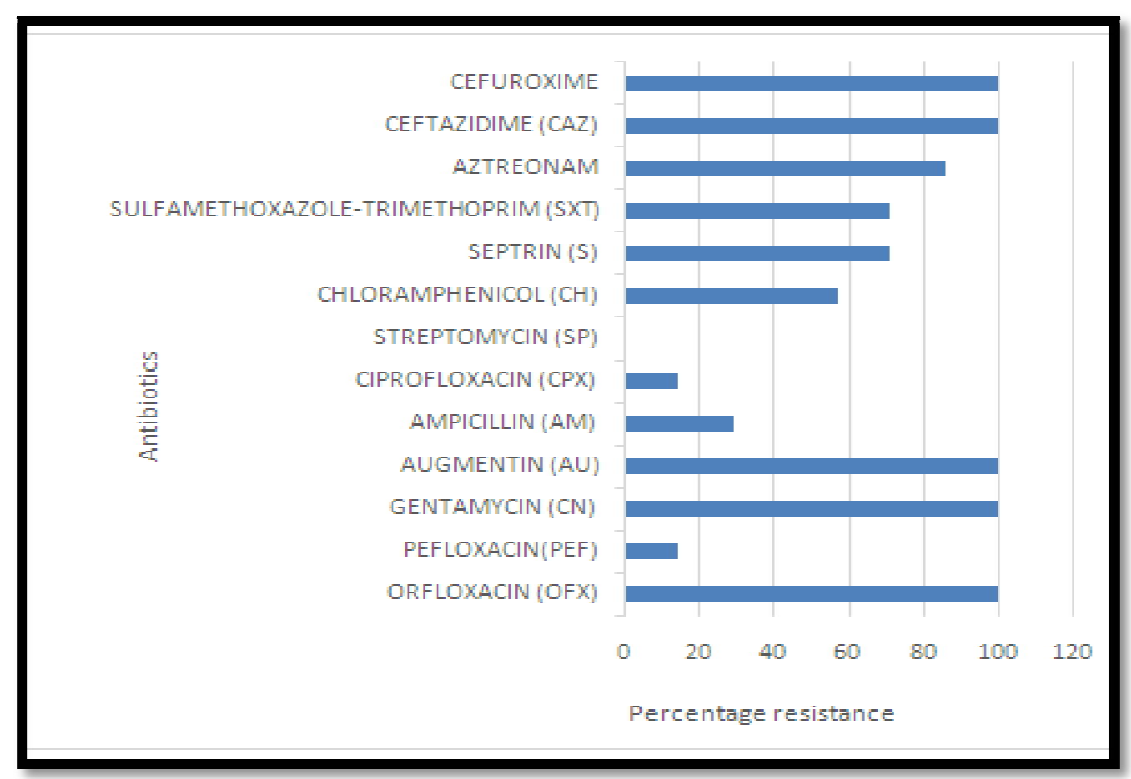

Figure 3: Percentage Antibiotics Resistance of MBL Producing Bacteria from Sachet Water

\begin{tabular}{|c|c|c|}
\hline Isolates & Resistance Pattern & MARI \\
\hline Proteus spp & OFX-CN-AUG-SXT-S-CXM-AZT-CAZ & 0.6 \\
\hline Citrobacter spp & OFX-CN-AUG-AMP-CPX-CH-SXT-CXM-AZT-CAZ & 0.8 \\
\hline Pseudomonas spp & OFX-CN-AUG-CH-SXT-S-CXM-AZT-CAZ & 0.7 \\
\hline Plesiomonas spp & OFX-CN-AUG-SXT-S-CXM-AZT-CAZ & 0.6 \\
\hline Pseudomonas spp & OFX-PEF-CN-AUG-AMP-CH-S-CXM-AZT-CAZ & 0.8 \\
\hline Aeromonas spp & OFX-CN-AUG-CXM-AZT-CAZ & 0.5 \\
\hline Salmonella spp & OFX-CN-AUG-CH-SXT-S-CXM-CAZ & 0.6 \\
\hline
\end{tabular}

Table 2: Antibiotics Resistance Spectrum and Multiple Antibiotics Resistance Indices (Mari) of Mbl Producing Bacterial Isolates from Sachet Water

\section{Discussion}

Imipenem is a beta-lactam antibiotic of the carbapenem class and acts on bacterial cell wall leading to the synthesis of a weak peptidoglycan. It is commonly used for the treatment of bacterial infections caused by ESBL producing pathogens. This has resulted in the increased use of these antibiotics, because they are resistant to most beta lactamases produced by bacteria (Gupta, 2008). The widespread use has led to a selective pressure for emergence of imipenem resistant bacteria. In this study, among the 50 gram-negative isolates, $70 \%$ showed full and intermediate resistance to imipenem while $30 \%$ were susceptible. Increased imipenem resistance has also been reported by other researchers worldwide (Mohammed and Raafat, 2011; Ahmed et al., 2011; Chika et al., 2017). In a study in India by Bashir et al (2011), $38(13.42 \%)$ of Pseudomonas isolates from a total of 283 isolates were resistant to Imipenem; Hemlatha et al. (2005) also reported that $16 \%$ of Pseudomonas isolates tested showed resistance to imipenem. Chika et al. (2014) reported $27 \%$ of the 99 isolates of the genera Escherichia, Klebsiella and Pseudomonas screened showed resistance to imipenem as well as showed MBL production. Similarly, a high resistance to imipenem was observed by Chika et al. (2016) among Esherichia coli and Klebsiella species isolates and also by Enwuru et al. (2011) who evaluated the occurrence of MBL producing Esherichia coli and Klebsiella species isolated from community and hospitalized subjects. Also, Panchal et al. (2017) stated $28 \%$ of a total of $107 \mathrm{gram}$ negative bacterial isolates were resistant to imipenem. This is rather alarming that a good number of gram-negative bacteria are developing resistance to this antibiotic. The consequence of this could be limited antibiotics options for treatment of both bacterial infections caused by ESBL and MBL producing pathogens. The underlying resistant mechanism could be any of the following resistant mechanisms: reduced outer membrane permeability, altered penicillin binding proteins, efflux pump and production of MBLs to modify the imipenem (Livermore, 2002).

To further determine the mode of resistance to imipenem, two phenotypic methods were employed to detect MBL production among the isolates. Using these methods, $29 \%$ and 54\% showed MBL production through the DDST and CDT phenotypic tests respectively while $20 \%$ produced MBL using both methods. A higher number of MBL positive isolates was observed using the CDT phenotypic test compared to the DDST. Similar trend was also observed by Anoar et al (2014) who reported $95.4 \%$ and $77.25 \%$ of the isolates showing MBL production by CDT and DDST methods respectively. Also, Prajapatiet al (2011) reported $96.30 \%$ and $81.4 \%$ of isolates as MBL producing bacteria using the CDT and DDST methods respectively. Panchal et al (2017) also observed the same trend between the CDT and DDST methods; using the CDT, 19(63.3\%) of the isolates were MBL positive while 16(53.3\%) were positive for MBL using the DDST. In other studies conducted in Nigeria, the MBL producing bacteria prevalence rates were $21.2 \%, 8.8 \%$ and $10 \%$ from Kaduna, Lagos and Enugu respectively (Yusuf et al., 2012; Ibukun and Odugbemi, 2007; Chika et al., 2014). Other isolates that showed no 
MBL production could have exhibited resistance to imipenem via other resistant mechanisms. These observations from different parts of the world show that imipenem resistance is gradually on the increase.

The antibiogram of the isolates confirmed to be MBL producers using two phenotypic methods showed that these bacteria were resistant to multiple antibiotics of different classes. The isolates were of the following genera Proteus spp, Pseudomonas spp, Aeromonas spp, andCitrobacter spp. All the isolates were only susceptible to streptomycin while $14 \%$ showed susceptibility to pefloxacin and ciprofloxacin. The highest resistance was observed against orfloxacin, gentamycin, augmentin, ceftazidime and cefuroxime. In agreement to the result obtained in this study, Nahid et al (2013), Gupta et al (2008), Kali et al (2013) and Peleg et al (2006) also recorded a high resistance to ceftazidime.Khosravi et al (2012) also reported MBL producing bacteria exhibiting multidrug resistance to at least six antibiotics. A high antibiotics resistance among environmental isolates had also been reported in Nigeria, Uganda, Netherlands (Ogunleye et al., 2008; Majalija et al., 2010; Van den Bogaard et al., 2001). From these observations, the MBL producing bacteria in this study were mostly susceptible to the aminoglycoside and fluoroquinolones and highly resistant to the beta lactams. This underscores the impact of MBL production on chemotherapy which reveals that few antibiotics are potent for the treatment of infections by MBL producing pathogens. The multiple antibiotics resistance indices (0.5-0.8) of the MBL producing isolates in this study further highlights the threat they constitute to treatment and control of infections (Toleman et al., 2005; Chika et al., 2017). Multidrug resistance of MBL producing bacteria to antibiotics ciprofloxacin, ceftazidime and aztreonam was also reported by Zubair and Iregbu (2018). The multidrug resistance can be attributed to both intrinsic and acquired traits which enable these isolates withstand the effects of various classes of antibiotics.

The dissemination and spread of the MBL producing bacteria through drinking of sachet water is a major concern. The presence of these MBL producing bacteria in the sachet water samples shows that the treatment methods were not very effective. These sachet water could serve as a major link between the transfer of genes encoding MBL to the human normal commensals and pathogens. Infections by such pathogens can be difficult to control given the multidrug resistance nature of MBL producing bacteria in this study. This effect can be so pronounced among individuals with compromised immune system, the neonates and aged.

\section{Conclusion}

The carbapenems are very important group of antibiotics that have been used over the years for treatment of serious bacterial infections especially those associated with extended spectrum beta lactamases. The emergence and rapid spread of the MBL producing bacteria is a threat to the carbapenems. Hence, to maintain the potency of these antibiotics in different regions of the world, their use should be strictly regulated and monitored. They should be used as the last resort antibiotics rather than using it empirically as the first line drug for treatment of any bacterial infections.

\section{References}

i. Ahmed, S. H., Abdelwahab, S. F., Hasanen, A. M., \& Mohammed, D. S. (2011). Multidrug resistant Egyptian isolates of Acinetobacter baumannii. J. Am. Sci, 7, 1013-1019.

ii. Alderson, R. G., Barker, D., \& Mitchell, J. B. (2014). One origin for metallo- $\beta$-lactamase activity, or two? An investigation assessing a diverse set of reconstructed ancestral sequences based on a sample of phylogenetic trees. Journal of molecular evolution, 79(3-4), 117-129.

iii. Ambler, R. P., Coulson, A. F., Frere, J. M., Ghuysen, J. M., Joris, B., Forsman, M., ... \& Waley, S. G. (1991). A standard numbering scheme for the class A beta-lactamases. Biochemical Journal, 276(Pt 1), 269.

iv. Anoar, K. A., Ali, F. A., \& Omer, S. A. (2014). Detection of metallo $\beta$-lactamase enzyme in some gram negative bacteria isolated from burn patients in Sulaimani City, Iraq. European Scientific Journal, ESJ, 10(3).

v. Bashir, D., Thokar, M. A., Fomda, B. A., Bashir, G., Zahoor, D., Ahmad, S., \& Toboli, A. S. (2011). Detection of metallobeta-lactamase (MBL) producing Pseudomonas aeruginosa at a tertiary care hospital in Kashmir. African Journal of Microbiology Research, 5(2), 164-172.

vi. Bebrone, C. (2007). Metallo- $\beta$-lactamases (classification, activity, genetic organization, structure, zinc coordination) and their superfamily. Biochemical pharmacology, 74(12), 1686-1701.

vii. Behera, B., Mathur, P., Das, A., Kapil, A., \& Sharma, V. (2008). An evaluation of four different phenotypic techniques for detection of metallo- $\beta$-lactamase producing Pseudomonas aeruginosa. Indian journal of medical microbiology, 26(3), 233.

viii. Blair, J. M., Webber, M. A., Baylay, A. J., Ogbolu, D. O., \& Piddock, L. J. (2015). Molecular mechanisms of antibiotic resistance. Nature Reviews Microbiology, 13(1), 42.

ix. Bush, K. (2013). The ABCD's of $\beta$-lactamase nomenclature. Journal of Infection and Chemotherapy, 19(4), 549-559.

X. Bush, K., \& Jacoby, G. A. (2010). Updated functional classification of $\beta$-lactamases. Antimicrobial agents and chemotherapy, 54(3), 969-976.

xi. Cantas, L., Shah, S. Q. A., Cavaco, L. M., Manaia, C., Walsh, F., Popowska, M., ... \& Sørum, H. (2013). A brief multidisciplinary review on antimicrobial resistance in medicine and its linkage to the global environmental microbiota. Frontiers in Microbiology, 4, 96.

xii. Chika, E., Charles, E., Ifeanyichukwu, I., Thaddeus, G., Malachy, U., Chika, E., \& Ikegbunam, M. N. (2017). Detection of Metallo- $\beta$-lactamase (MBL) among Carbapenem-Resistant Gram-Negative Bacteria from Rectal Swabs of Cow and Cloacae Swabs of Poultry Birds. Annals of Medical and Health Sciences Research.

xiii. Chika, E., Peter, E., Eucharia, O., Chika, E., Ovia, K., Ifeanyichukwu, I., \& Charles, E. (2017). Plasmid Curing, BetaLactamase Production, Antibiogram and Metallo--lactamase (MBL) Detection in Escherichia coli and Klebsiella Species from Non-Hospital Sources of Abattoir and Poultry. 
xiv. Enwuru, N. V., Enwuru, C. A., Ogbonnia, S. O., \& Adepoju-Bello, A. A. (2011). Metallo- $\beta$-lactamase production by Escherichia coli and Klebsiella species isolated from hospital and community subjects in Lagos, Nigeria. Nat Sci, 9(11), 1-5.

xv. Franklin, C., Liolios, L., \& Peleg, A. Y. (2006). Phenotypic detection of carbapenem-susceptible metallo- $\beta$ lactamase-producing gram-negative bacilli in the clinical laboratory. Journal of clinical microbiology, 44(9), 31393144.

xvi. Gupta, V. (2008). Metallo beta lactamases in Pseudomonas aeruginosa and Acinetobacter species. Expert opinion on investigational drugs, 17(2), 131-143.

xvii. Hall, B. G., Salipante, S. J., \& Barlow, M. (2003). The metallo- $\beta$-lactamases fall into two distinct phylogenetic groups. Journal of molecular evolution, 57(3), 249-254.

xviii. Hemalatha, V., Sekar, U., \& Kamat, V. (2005). Detection of metallo betalactamase producing Pseudomonas aeruginosa in hospitalized patients. Indian Journal of Medical Research, 122(2), 148.

xix. Hocquet, D., Muller, A., \& Bertrand, X. (2016). What happens in hospitals does not stay in hospitals: antibioticresistant bacteria in hospital wastewater systems. Journal of Hospital Infection, 93(4), 395-402.

xx. Ibukun Aibinu, T. N., \& Odugbemi, T. (2007). Occurrence of ESBL and MBL in Clinical Isolates of Pseudomonas aeruginosa From Lagos, Nigeria. Antimicrobial agents and chemotherapy, 3, 81-85.

xxi. Jesudason, M. V., Kandathil, A. J., \& Balaji, V. (2005). Comparison of two methods to detect carbapenemase \& metallo-[beta]-lactamase production in clinical isolates. Indian Journal of Medical Research, 121(6), 780.

xxii. Kali, A., Srirangaraj, S., Kumar, S., Divya, H. A., Kalyani, A., \& Umadevi, S. (2013). Detection of metallo-betalactamase producing Pseudomonas aeruginosa in intensive care units. The Australasian medical journal, 6(12), 686.

xxiii. Khosravi, Y., Loke, M. F., Chua, E. G., Tay, S. T., \& Vadivelu, J. (2012). Phenotypic detection of metallo- $\beta$-lactamase in imipenem-resistant Pseudomonas aeruginosa. The Scientific World Journal, 2012.

xxiv. Livermore, D. M. (2002). Multiple mechanisms of antimicrobial resistance in Pseudomonas aeruginosa: our worst nightmare? Clinical infectious diseases, 34(5), 634-640.

xxv. Livermore, D. M. (2008). Defining an extended-spectrum $\beta$-lactamase. Clinical Microbiology and Infection, 14(s1), 3-10.

xxvi. Majalija, S., Francis, O., Sarah, W. G., Vudriko, P., \& Nakamya, F. M. (2010). Antibiotic susceptibility profiles of fecal Escherichia coli isolates from dip-litter broiler chickens in Northern and Central Uganda. Veterinary Research (Pakistan), 3(4), 75-80.

xxvii. Martínez, J. L. (2008). Antibiotics and antibiotic resistance genes in natural environments. Science, 321(5887), 365-367.

xxviii. Mohamed, N. M., \& Raafat, D. (2011). Phenotypic and genotypic detection of metallo-beta-lactamases in imipenemresistant Acinetobacter baumannii isolated from a tertiary hospital in Alexandria, Egypt. Research Journal of Microbiology, 6(10), 750.

xxix. Nahid, F., Khan, A. A., Rehman, S., \& Zahra, R. (2013). Prevalence of metallo- $\beta$-lactamase NDM-1-producing multidrug resistant bacteria at two Pakistani hospitals and implications for public health. Journal of infection and public health, 6(6), 487-493.

xxx. Navaneeth, B. V., Sridaran, D., Sahay, D., \& Belwadi, M. R. S. (2002). A preliminary study on metallo-[beta]lactamase producing Pseudomonas aeruginosa in hospitalized patients. Indian Journal of Medical Research, 116, 264.

xxxi. Niederman, M. S. (2001). Impact of antibiotic resistance on clinical outcomes and the cost of care. Critical care medicine, 29(4), N114-N120.

xxxii. Nordmann, P., Poirel, L., Walsh, T. R., \& Livermore, D. M. (2011). The emerging NDM carbapenemases. Trends in microbiology, 19(12), 588-595.

xxxiii. Ogunleye, A. O., Oyekunle, M. A., \& Sonibare, A. O. (2008). Multidrug resistant Escherichia coli isolates of poultry origin in Abeokuta, South Western Nigeria. Veterinarski Arhiv, 78(6), 501-509.

xxxiv. Panchal, C. A., Oza, S. S., \& Mehta, S. J. (2017). Comparison of four phenotypic methods for detection of metallo- $\beta$ lactamase-producing Gram-negative bacteria in rural teaching hospital. Journal of laboratory physicians, 9(2), 81.

xxxv. Paphitou, N. I. (2013). Antimicrobial resistance: action to combat the rising microbial challenges. International journal of antimicrobial agents, 42, S25-S28.

xxxvi. Peleg, A. Y., Franklin, C., Bell, J. M., \& Spelman, D. W. (2006). Emergence of carbapenem resistance in Acinetobacter baumannii recovered from blood cultures in Australia. Infection Control \& Hospital Epidemiology, 27(7), 759-761.

xxxvii. Philippon, A., Slama, P., Dény, P., \& Labia, R. (2016). A structure-based classification of class A $\beta$-lactamases, a broadly diverse family of enzymes. Clinical microbiology reviews, 29(1), 29-57.

xxxviii. $\quad$ Prajapati, S. B., Vegad, M. M., Mehta, S. J., Kikani, K. M., Kamothi, M. N., \& Pandya, J. M. (2011). An evaluation of two different phenotypic methods for detection of metallo-[beta]-lactamase producing Pseudomonas isolates. Journal of Cell and Tissue Research, 11(1), 2601.

xxxix. Queenan, A. M., \& Bush, K. (2007). Carbapenemases: the versatile $\beta$-lactamases. Clinical microbiology reviews, 20(3), 440-458.

xl. Senda, K., Arakawa, Y., Ichiyama, S., Nakashima, K., Ito, H., Ohsuka, S., ... \& Ohta, M. (1996). PCR detection of metallo-beta-lactamase gene (blaIMP) in gram-negative rods resistant to broad-spectrum beta-lactams. Journal of clinical microbiology, 34(12), 2909-2913. 
xli. Toleman, M. A., Biedenbach, D., Bennett, D. M., Jones, R. N., \& Walsh, T. R. (2005). Italian metallo- $\beta$-lactamases: a national problem? Report from the SENTRY Antimicrobial Surveillance Programme. Journal of Antimicrobial Chemotherapy, 55(1), 61-70.

xlii. Tzouvelekis, L. S., Markogiannakis, A., Psichogiou, M., Tassios, P. T., \& Daikos, G. L. (2012). Carbapenemases in Klebsiella pneumoniae and other Enterobacteriaceae: an evolving crisis of global dimensions. Clinical microbiology reviews, 25(4), 682-707.

xliii. Van den Bogaard, A. E., London, N., Driessen, C. A. G. G., \& Stobberingh, E. E. (2001). Antibiotic resistance of faecal Escherichia coli in poultry, poultry farmers and poultry slaughterers. Journal of Antimicrobial Chemotherapy, 47(6), 763-771.

xliv. Voulgari, E., Poulou, A., Koumaki, V. \& Tsakris, A. Carbapenemase-producing Enterobacteriaceae: now that the storm is finally here, how will timely detection help us fight back? Future Microbiol. 8, 27-39 (2013).

xlv. Walsh, T. R., Toleman, M. A., Poirel, L., \& Nordmann, P. (2005). Metallo- $\beta$-lactamases: the quiet before the storm? Clinical microbiology reviews, 18(2), 306-325.

xlvi. Wang, Z., Fast, W., Valentine, A. M., \& Benkovic, S. J. (1999). Metallo- $\beta$-lactamase: structure and mechanism. Current opinion in chemical biology, 3(5), 614-622.

xlvii. Yusuf, I., Yusha'u, M., Sharif, A. A., Getso, M. I., Yahaya, H., Bala, J. A., ... \& Haruna, M. (2012). Detection of metallo betalactamases among gram negative bacterial isolates from Murtala Muhammad Specialist Hospital, Kano and Almadina Hospital Kaduna, Nigeria. Bayero Journal of Pure and Applied Sciences, 5(2), 84-88.

xlviii. Zubair, K. O., \& Iregbu, K. C. (2018). Resistance pattern and detection of metallo beta lactamase genes in clinical isolates of Pseudomonas aeruginosa in a central Nigeria Tertiary Hospital. Nigerian journal of clinical practice, 21(2), 176-182. 